Article

\title{
Leading Proactivity in Innovative Startups: A Moderated Mediation Model
}

\author{
Mario Martínez-Córcoles ${ }^{1, *}$ and Xi Zhu ${ }^{2}$ (D) \\ 1 Department of Psychology, University of Valladolid, 34004 Palencia, Spain \\ 2 Department of Business Administration, Tallinn University of Technology, 12616 Tallinn, Estonia; \\ marcuszhu12@gmail.com \\ * Correspondence: mario.martinez.corcoles@uva.es
}

Received: 6 November 2020; Accepted: 24 November 2020; Published: 26 November 2020

\begin{abstract}
Despite the growing research interest in proactivity, little is known about the relational mechanisms that cultivate individuals' proactivity in the workplace. This research aims to explore the leader-follower relational mechanisms leading to employee proactive performance in innovative startups. The sample consisted of 83 employees from eleven startups. Conditional process modeling was conducted to explore the background relational mechanisms of employee proactive performance. Employees with upward psychological safety (who felt safe to speak up and contribute in front of their leaders) were willing to go beyond their formal roles and job descriptions for the sake of the firm (challenging role orientation). In turn, this orientation predicted self-directed efforts and initiated better ways of doing their job (proactive performance). Under high levels of perceived uncertainty, upward psychological safety was a stronger predictor of proactive performance through a challenging role orientation. This study reveals that upward psychological safety is critical for enhancing employee proactivity at work, particularly under high uncertainty.
\end{abstract}

Keywords: proactive performance; proactivity; innovation; psychological safety; uncertainty; work attitudes; sustainable management; startups

\section{Introduction}

Startup companies are small new businesses designed to adapt and grow in highly competitive and uncertain environments [1]. Constant pressure for continual improvement and innovation push these companies to rely on employees' personal initiative to identify and solve emerging problems [2]. In these organizations, employees are no longer expected to passively follow instructions, task descriptions, and orders [3]. Instead, they are encouraged to use their initiative and act proactively to contribute to the firm's growth.

Despite the growing research interest in proactivity, reflecting the increasing importance of this type of behavior for innovation [4], scholars have gained little insight into the leader-follower relational mechanisms that cultivate individuals' proactivity in the workplace. For this reason, our aim in the present study is to explore the leader-follower relational aspects leading to followers' proactive performance in innovative startups. To do so, we studied eleven startups from the Baltic region (Estonia, Finland, and Lithuania). Drawing on a distal-proximal model of proactive performance [5] and on Edmondson's psychological safety theory [6,7], we hypothesize that employees who feel safe to speak up and contribute in front of their leaders (with upward psychological safety) are willing to go beyond their formal roles for the sake of the firm (challenging role orientation), resulting in enhanced proactive performance. We also expect that under high levels of perceived uncertainty, upward psychological safety is a stronger predictor of proactive performance through a challenging role orientation. 
This study adds to previous literature in three main ways. First, psychological safety has traditionally been defined as an overall team climate where members feel comfortable expressing themselves and sharing ideas and concerns without fear of embarrassment or retribution [6]. However, there can be great variations in a person's psychological safety levels depending on the other members' characteristics, such as their power or status [8]. Taking into consideration that an employee's psychological safety could be completely different from that of their peers or the leader, we refined the concept of psychological safety towards the leader-follower relationship (namely, upward psychological safety). Second, whereas research on psychological safety has mainly focused on its direct effects on proactive-related behaviors [9-11], this study explores the path through which upward psychological safety exerts its influence on proactive performance. Third, according to [4], more research is needed to discover whether situational stressors have promoting [12] or inhibiting [13] effects on proactive performance. In this study, we explore how a situational stressor (uncertainty) affects the impact of upward psychological safety on proactive performance.

\subsection{Contextualizing Proactive Performance in the Knowledge Economy}

A productive economy focused on maximum production at the lowest cost has permeated work and organizations for decades. Organizations following the productive logic have been operating as hierarchical pyramids where power is distributed linearly top-down, and where individuals higher in the ranks are granted power and authority over those below them [14]. In this traditional top-down management paradigm, leaders/bosses must tell others what to do to meet organizational goals, not only because bosses are higher in the hierarchy, but also because it is assumed that they have greater technical knowledge and skills $[15,16]$. This assumption that leaders have the obligation to tell others what to do entails the internalization of compatible assumptions, such as that employees should limit themselves to following instructions and role descriptions as best as they can without speaking up much, or employees should not tell their leaders they are wrong [3].

However, a global transition from a productive economy to a knowledge economy is taking place [17], and the business world is experiencing two major changes in this regard. On the one hand, the socioeconomic environment where companies are embedded is becoming more interdependent, complex, and, therefore, difficult to predict (uncertain). On the other hand, market competition is not only based on price, as it was a few decades ago; instead, it depends particularly on knowledge and innovation [18]. In theory, the traditional top-down management paradigm described above is becoming obsolete due to these changes because, more than ever, organizations need employees' engagement and participation in the process of identifying and responding to threats and opportunities [19]. However, in practice, organizational scholars and professionals widely acknowledge that the traditional paradigm still predominates in our minds as a learned set of underlying assumptions about how work relationships have to be $[14,16]$. The dramatic pace of the change is exceeding people's ability to alter their underlying basic assumptions accordingly, and the insecurity of an uncertain environment exacerbates companies' tendency to retract and play it safe. As a result, much of the business world is still stuck in the past [14], using conservative managerial approaches to keep systems under control [20], such as obsessive supervision and continuous monitoring of process execution and costs, or preventing employees' deviation from roles and norms. Nevertheless, in a business environment where knowledge and innovation are the key to remaining competitive and surviving, companies need to manage and organize in new organic and decentralized ways that allow employees to engage in proactive behavior, in order to promote creativity, innovation, and change [21-26].

Proactive performance is defined as self-initiated efforts to make progress, predict and manage problems, and capture opportunities [27]. According to different authors, today's workers not only have to react to change, but they also have to anticipate and act upon the external environment in self-directed ways to achieve effective outcomes $[28,29]$. The need for individual proactivity is particularly great in startups because product and service specialization are accelerating and require continual improvement and innovation. In this case, work roles must emerge dynamically in response 
to changing conditions and demands [30], and workers need to identify improved ways of working under their own initiative, without relying on directions from supervisors [21,29,31]. Therefore, proactive performance may be more important than ever before [22].

Research on situational variables as predictors of proactive performance remains scarce and inconclusive. In the case of leadership, a growing body of recent research has pointed out that positive leader behaviors, such as support or empowerment, appear to promote proactivity, whereas negative leader behaviors such as aggressive or abusive behaviors inhibit proactivity. Although these findings help us understand the valence of leader behaviors on employee proactivity, the pathways remain blurry and unsolved. Rather than simply testing if a specific leadership style or behavior has a positive or negative effect on employee proactivity, future studies should explore how it does so. Moreover, it is important to understand how specific leadership actions interact with the contexts and circumstances, thereby understanding how situational variables influence leaders' ability to promote proactive performance. We therefore propose an integrated model to examine the path in which a specific supportive supervision (upward psychological safety) affects followers' proactive performance under the influence of uncertainty.

\subsection{A Distal-Proximal Model of Proactive Performance}

For a more in-depth examination of the antecedents of proactive performance, we use a distal-proximal framework. This approach concurs with previous works $[4,5,23]$ proposing that environmental variables are distal causes of proactive performance that exert their effect through more proximal variables, such as cognitively oriented motivational processes. In this article, we propose upward psychological safety as a distal antecedent of proactive performance that partially exerts its influence via a challenging role orientation (proximal antecedent).

\subsubsection{Challenging Role Orientation as Proximal Antecedent of Proactive Performance}

The need for adaptive and flexible ways of organizing makes employees who are willing to go beyond the rigid and formal job description a source of competitive advantage for any organization [24]. The willingness to move beyond mere task descriptions and become involved in increasingly challenging demands in order to have a greater impact on overall organizational effectiveness is called a challenging role orientation (or flexible role orientation). Although the challenging role orientation shares similarities with other constructs such as organizational citizenship (OCB) or proactive behavior, it has been found to be independent from them [24]. Although all these constructs result from a motivational state, a challenging role orientation is conceptualized as an attitude or disposition, whereas OCB and proactive behavior are behavioral outcomes [32].

Goal Setting Theory [33] is a suitable framework for understanding the relationship between the role orientation (attitude) and proactive performance (behavior). According to this theory, specific and challenging goals lead to better performance than having no goals, unclear goals, or do your best goals. Two field studies [34] empirically supported this rationale, revealing that employees' role orientation is a powerful influence on their performance. Indeed, in both studies, the role orientation was a stronger predictor of performance than other work attitudes such as self-efficacy, locus of control, or job satisfaction.

In this regard, a challenging role orientation is a cognitive-oriented motivational process that is particularly relevant in guiding proactive performance [5,34]. The employee's willingness to move away from the "that's not my job" mentality to a more generous orientation (where being self-directed, using initiative, and expanding knowledge are seen as key aspects of one's job) increases self-directed behaviors and leads individuals to initiate better ways of doing their job (i.e., proactive performance) $[24,35,36]$. 


\subsubsection{Upward Psychological Safety as Distal Antecedent of Proactive Performance}

As mentioned above, one of the common beliefs of the traditional management paradigm is that the leader possesses higher technical knowledge and skills than the followers. But growing technological complexity, operational uncertainty, and occupational specialization are overwhelming leaders' capacity to identify threats and opportunities [37]. It is therefore likely that leaders are no longer capable of predicting all the possible situations or having all the necessary information and knowledge to make the best decisions unilaterally. In the knowledge era, the boss will still be the boss, but instead of telling others how to do the job (traditional top-down paradigm), they will have to learn how to enhance followers' engagement in decision-making and implementation in order to achieve better and more effective solutions (new paradigm).

The research interest in this new management paradigm has brought interesting leadership theories and models, revealing, for instance, the benefits of participative leadership styles for followers' proactive performance [38] for transformational leadership, or for shared leadership [39]. However, these research findings frequently deal with stories of practitioners struggling with the upward communication breakdown [40] associated with the traditional paradigm. This breakdown occurs when the leader's attempts to achieve employees' proactive contributions are not fruitful because followers still frequently believe that voicing new ideas, having a questioning attitude, or initiating extra-role behaviors might challenge the traditional way of doing things and go beyond the subordinate's mission [9,41,42]. For this reason, employees perceive that this contribution has associated risks for them [42], and they prefer to stay safe by refusing to initiate self-directed actions. Therefore, it is still the leaders' responsibility to reduce the formal distance with their followers by creating an environment where symmetric interactions with their subordinates and mutual help take place. In this regard, leaders play a key role in creating what is called "psychological safety" $[6,10]$ that is, an atmosphere where employees feel safe to speak up and contribute their ideas and concerns [6,43]. Psychological safety has been positively related to employee performance, creativity, engagement, and knowledge sharing [42,44,45] for extended reviews on psychological safety.

In the past few years, psychological safety has been studied as an overall shared belief that the team is a safe environment for interpersonal risk taking [6]. In other words, employees experience psychological safety when they feel that their teammates will not reject people for expressing themselves or saying what they think, that they will respect each other's competence and have positive intentions toward one another, and that they will be able to engage in constructive confrontation and feel that it is safe to experiment and take risks [6,42]. However, not all colleagues generate the same level of trust [8], and an employee might feel different levels of psychological safety depending on other people's characteristics. For instance, one of the determining characteristics is power or hierarchical status $[46,47]$. An employee behaving genuinely can feel completely safe with his/her peers (equal power or status), but at risk in front of her/his superior (unequal power or status). Taking into consideration the important role of formal leaders in creating psychological safety in their employees and the leader-follower power dynamics, we are especially interested in exploring psychological safety, not as an overall team-climate phenomenon, but as an individual belief based on the follower-leader relationship. Therefore, following Edmondson's definition of psychological safety [7], we define upward psychological safety as the followers' belief that they are free to speak up and contribute ideas and concerns in front of the superior without fear of embarrassment or retribution.

According to the Theory of Planned Behavior [48,49], individuals make systematic use of information available to them and consider the implications of their actions before they decide whether or not to engage in a given behavior. Based on this theory, when one has guarantees that their initiated self-directed behaviors will be accepted and recognized from the top (positive implications), they will be willing to take the risk of contributing beyond their formal role (challenging role orientation). That is, being challenge-oriented at work requires the belief that one will be not punished or humiliated for speaking up or taking self-directed action (psychological safety). Therefore, we expect upward psychological safety to be a trigger for an individual's challenging orientation, which will lead them to 
perform proactively. If upward psychological safety is low, the follower will try to stay safe by following their prescribed role, and it is unlikely that initiative or proactive performance will emerge. Conversely, if upward psychological safety is high, it becomes possible for the employee to be willing to contribute and initiate new action beyond their formal role without fear, making proactive behaviors much more likely to occur. Taking these arguments into consideration, our first hypothesis is the following:

Hypothesis 1. Upward psychological safety will positively and indirectly predict proactive performance by means of a challenging role orientation.

A wide range of studies suggest that leader behaviors that are relevant to building a good relationship with employees enhance engagement and proactive-related behaviors via psychological safety [50,51]. For instance, it has been shown that leader inclusiveness predicts engagement in quality improvement work through psychological safety [10]. Transformational leadership and managerial openness increase psychological safety [9], which, in turn, enhanced employee voice. In a similar vein, it was found that ethical leadership influenced voice via psychological safety [11]. These studies situating psychological safety as a direct trigger of proactive-related behaviors in the workplace suggest that, despite being proposed as a distal antecedent, upward psychological safety might have a direct effect on proactive performance. That is, upward psychological safety might not only create a willingness to go beyond one's prescribed role (challenging role orientation) and act proactively, but it could also spontaneously and directly promote proactive behaviors. Thus, it is expected that upward psychological safety will be a direct antecedent that will positively and directly predict employees' proactive performance.

Hypothesis 2. Upward psychological safety will positively and directly predict proactive performance.

\subsection{The Role of Uncertainty}

Uncertainty occurs when significant information is missing or inconsistent [52] and there is a lack of knowledge about what outcomes are possible [53]. Uncertainty is a subjective phenomenon because there may be important interpersonal differences when coping with the same situation [54]. The same situation may cause excessive uncertainty for one individual, but negligible uncertainty for another [55]. In this regard, our conceptualization of uncertainty relies on the individual's perception of uncertainty rather than on an objective measure.

The unpredictability of an uncertain environment leads employees to adhere to the prescribed role and stay safe [56]. For this reason, it is suggested that when uncertainty is present, the need to confront and overcome interpersonal risk is more salient and, therefore, psychological safety has more weight [45]. In line with this argument, we believe that upward psychological safety could have a stronger effect on proactive performance through employees' role orientation. To build this hypothesis, we draw on the four premises of Edmondson's model of psychological safety [7].

The first premise of Edmondson's model suggests that employees working in predictable and low demanding environments who do not feel free to speak up and contribute will experience apathy. Correspondingly, employees who must adhere to prescribed routines (low uncertainty) without feeling safe with their leader (low upward psychological safety) are expected to adopt the "that's not my job" mentality and, therefore, an indifferent work orientation (see Figure 1, Quadrant 1). The second premise states that workers in predictable and low challenging work environments who feel safe to speak up and contribute will find themselves in a comfort zone. Likewise, employees involved in prescribed routines (low uncertainty), but with the possibility of speaking up and showing themselves freely in front of their leader (high upward psychological safety), may develop a friendly and easy-going work orientation (Quadrant 2). The third premise points out the worrisome situation of employees with a highly demanding and uncertain environment but no psychological safety, due to the anxiety these conditions produce. Indeed, employees experiencing high levels of uncertainty who do not feel upward 
safe (high uncertainty, low upward psychological safety) will avoid putting themselves at risk and limit themselves to following commands formally, thus adopting an obedience work orientation (Quadrant 3). In the fourth premise, Edmondson indicates that when employees working in highly demanding and uncertain settings feel psychologically safe, they will devote themselves fully to the challenging tasks ahead. Only when workers experience high uncertainty and high upward psychological safety will they be motivated to give their best response to an emerging problem (taking a challenging role orientation) (Quadrant 4).

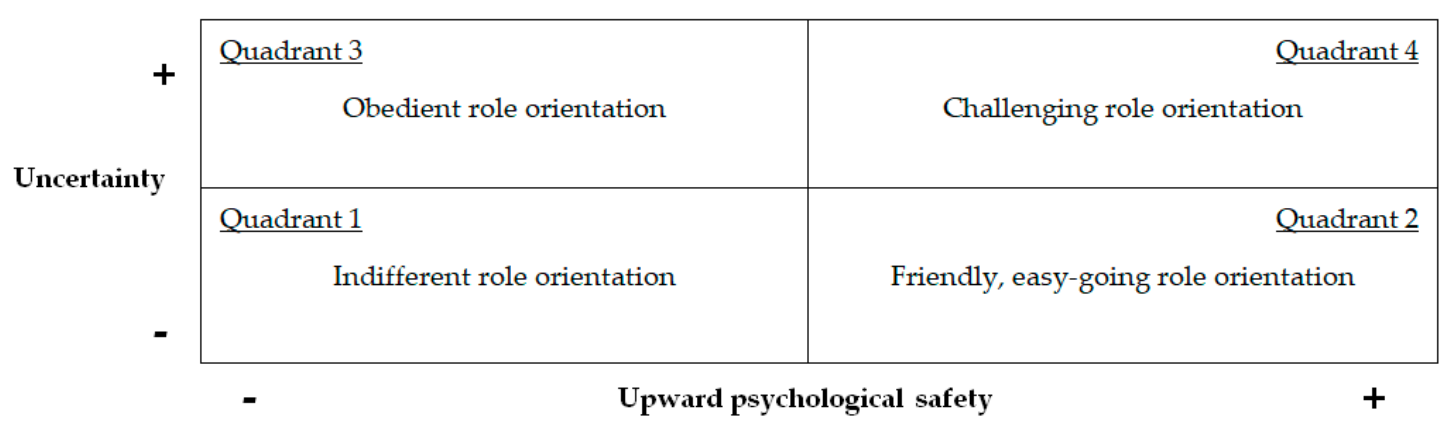

Figure 1. Model of employee role orientation under the effects of the interaction between uncertainty and upward psychological safety, based on Edmondson's theory of psychological safety [7].

According to the aforementioned arguments, it is expected that uncertainty increases the effect of upward psychological safety on a challenging role attitude, resulting in enhanced proactive performance.

Hypothesis 3. Uncertainty will moderate the positive effect between upward psychological safety and a challenging role orientation, resulting in enhanced proactive performance.

\section{Materials and Methods}

\subsection{Sample and Procedure}

Our sample was composed of 83 individuals from 11 innovation-based startups in the Baltic region (Estonia (4 startups; 23 individuals in total), Finland (5 startups; 51 individuals in total), and Lithuania (2 startups; 9 individuals in total)). Industries included IT, fintech, and entertainment. In order to determine the sample size needed, a power analysis was conducted using $G^{*}$ Power [57]. With a medium effect size $\left(f^{2}\right)$ of 0.15 , an alpha of 0.05 , a standard power level of 0.80 , and a total of 3 predictors, the results of the power analysis showed that a minimum of 77 participants were needed to achieve an appropriate power level for this study [58]. The average response rate was $42 \%$. Participant demographic data are presented in Table 1. All responses were anonymous and processed only in aggregate format. Due to the sensitive nature of questions about workplace interpersonal dynamics, all questionnaires were administered on a voluntary basis. Questionnaires were distributed electronically through LimeSurvey, as part of a wider battery of questionnaires produced to evaluate organizational performance. The questionnaire took an average of 12-15 min to complete. Data were collected over a period of two months, from January to March, 2018, and they were processed by SPSS 23.0 [59] and Amos 23.0 [60]. 
Table 1. Participant demographic data.

\begin{tabular}{|c|c|c|c|}
\hline & Category & Number & Undisclosed \\
\hline \multirow{2}{*}{ Gender } & Male & $27(32.5 \%)$ & \multirow{2}{*}{$10(12 \%)$} \\
\hline & Female & $46(55.4 \%)$ & \\
\hline \multirow{3}{*}{ Age (years) } & $18-35$ & $47(56.6 \%)$ & \multirow{3}{*}{$10(12 \%)$} \\
\hline & $36-50$ & $22(26.5 \%)$ & \\
\hline & 51 or more & $4(4.8 \%)$ & \\
\hline \multirow{4}{*}{ Work experience in similar fields (years) } & less than 3 & $25(30.1 \%)$ & \multirow{4}{*}{$10(12 \%)$} \\
\hline & $4-6$ & $27(32.5 \%)$ & \\
\hline & 7-11 & $12(14.5 \%)$ & \\
\hline & 12 or more & $9(10.8 \%)$ & \\
\hline \multirow{3}{*}{ Department/Area of work } & Field/Customer related & $29(34.9 \%)$ & \multirow{3}{*}{$37(44.6 \%)$} \\
\hline & Office work & $15(18.1 \%)$ & \\
\hline & Management & $2(2.4 \%)$ & \\
\hline Total & & 83 & \\
\hline
\end{tabular}

To determine the possible effect of organizational nationality on responses, a one-way between-groups ANOVA was performed using SPSS 23.0 [59]. Results demonstrated no statistically significant differences among these countries for upward psychological safety $(\mathrm{F}(2,80)=0.691$, $p=0.504)$, uncertainty $(\mathrm{F}(2,80)=0.643, p=0.529)$, challenging role orientation $(\mathrm{F}(2,80)=0.193$, $p=0.825)$, or proactive performance $(\mathrm{F}(2,80)=1.451, p=0.241)$.

\subsection{Measurement}

Upward psychological safety was measured with the scale by Martínez-Córcoles et al. [61] which evaluates to what extent the employee feels free to speak up and contribute ideas and concerns in front of his/her leader. This scale consists of three items rated on a 5-point Likert response scale ranging from 1 (strongly disagree) to 5 (strongly agree). Items were: "I can express my disagreements with my superior freely"; "I can tell my superior when things are going wrong"; "I feel free to talk with my superior about problems and difficulties I have in my work without fear." The internal consistency reliability for this measure was 0.92 .

To measure uncertainty, we adopted the scale by Colquitt et al. [62]. Participants answered four items on a 5-point Likert response scale, ranging from 1 (completely disagree) to 5 (completely agree). Items were: "There is a lot of uncertainty at work right now"; "Many things currently seem unsettled at work"; "If I think about work, I feel a lot of uncertainty"; "I cannot predict how things will go at work." The internal consistency reliability for this measure was 0.87 .

Challenging role orientation was measured using five items that corresponded to the measurement of "increasing challenging demands" by Tims et al. [63]. We used this scale because the items assess the employee's willingness to voluntarily accept higher intensity at work. Each item was answered on a 7-point Likert scale ranging from 1 (strongly disagree) to 7 (strongly agree). Participants were asked to think about their current job and then indicate how much they agreed or disagreed with the different statements. Some of the statements were: "If there are new developments, I am one of the first to learn about them and try them out"; "When there is not much to do at work, I see it as a chance to start new projects"; "I regularly take on extra tasks even though I do not receive extra salary for them". The internal consistency reliability for this measure was 0.75 .

Proactive performance was measured with the performance model scale designed by Griffin et al. [29]. Although the scale included both individual and team dimensions, we selected only individual proactive performance for the present research. Three items were used to measure individual proactive performance. Participants were asked to rate their behavior by responding to the question: "How often have you carried out the behavior in the past month?" on a five-point Likert scale, from 1 (very little) to 5 (a great deal). Items included: "Initiated better ways of doing your core 
tasks"; "Come up with ideas to improve the way in which your core tasks are done"; "Made changes to the way your core tasks are done." The internal consistency reliability for this measure was 0.87 .

\subsection{Preliminary Analyses: Testing Construct Validity and Common Method Bias}

The first step in the data analysis was to test the factorial structure of the scales used in our sample, in order to obtain evidence of their construct validity. To that end, we performed two confirmatory factor analyses (CFA) using LISREL 8.80 [64]. Robust Maximum Likelihood (ML) was used to estimate model parameters, and considering the ordinal nature of the variables, both the polychoric correlations matrix and the asymptotic covariances matrix were used as input for the analyses.

The scales were included in the same battery of questionnaires (participants responded to the scales sequentially and immediately), and the method used was the same for all respondents. Therefore, we first conducted a confirmatory factor analysis using the four scales together. Upward psychological safety, uncertainty, challenging role orientation, and proactive performance were introduced as one-dimensional scales. Second, we examined the possibility that a single factor could emerge for all four constructs, taking into account that common variance could inflate the associations among the study variables. To explore this possibility, we conducted a second confirmatory factor analysis in which all the items in the four variables loaded in a single factor. Thus, a Harman Single Factor test was carried out using the Confirmatory Factor Analysis method [65]. Its basic assumption is that if a substantial amount of common method variance is present, either a single factor will emerge from the factor analysis or one general factor will account for the majority of the covariance among the measures, with all items loading in this single factor. In order to assess the fit of the models, we examined the RMSEA (root mean square error of approximation), CFI (comparative fit index), and NNFI (non-normed fit index). The interpretation of these indexes is the following: RMSEA $<0.08=$ acceptable model $[66,67]$; CFI $>0.90=$ acceptable model, and $>0.95=$ excellent model [68]; and NNFI $>0.90=$ acceptable model and $>0.95=$ excellent model [68].

Additionally, to assess the impact of common method variance (CMV) on our self-report data format, a CFA marker technique [69] using Amos 23.0 [60] was used following the steps outlined by Williams et al. [70], with uncertainty selected as the post-hoc marker variable. Although the ideal marker variable should be determined a priori and is intended to specifically assess CMV, we consider uncertainty to be an acceptable marker variable. Because uncertainty is an environmental-based report rather than a behavioral-based report, it is conceptually different from the other variables involved (psychological safety, challenging role orientation, and proactive performance) and guarantees theoretical distance from them. This distinction is supported by the ambiguous effects of uncertainty on employee behavior [71,72]. Furthermore, uncertainty as the marker variable shares common CMV sources with the substantive variables, a criterion discussed by Simmering et al. [73]. For example, self-enhancement is a common CMV between the uncertainty item "If I think about work, I feel a lot of uncertainty" and the challenging role orientation item "When there is not much to do at work, I see it as a chance to start new projects" or the proactive performance item "Come up with ideas to improve the way in which your core tasks are done".

\subsection{Hypothesis Testing Analyses}

To test Hypotheses 1 and 2, we conducted a mediation analysis with PROCESS macro [74] in SPSS 23.0 [59], using a 5000-sample bootstrapping method with bias-corrected confidence estimates. Bootstrap resampling procedures establish confidence intervals (CIs) set to $95 \%$ for testing the statistical significance of indirect results. To test Hypothesis 3, we conducted moderated mediation analyses with PROCESS SPSS macro (74), using the bias-corrected bootstrap method considered in the mediation analyses. The variables used as a component of the interaction term were mean-centered to create more meaningful and substantially interpretable tests of hypotheses and regression coefficients [74]. Descriptive statistics are presented in Table 2. 
Table 2. Descriptive statistics and correlations between variables.

\begin{tabular}{ccccccc}
\hline Variable & M & SD & $\mathbf{1}$ & $\mathbf{2}$ & $\mathbf{3}$ & $\mathbf{4}$ \\
\hline Upward psychological safety & 4.09 & 0.97 & - & & & \\
Proactive performance & 3.59 & 0.88 & $0.29^{* *}$ & - & & \\
Challenging role orientation & 4.26 & 0.92 & $0.48^{* *}$ & $0.55^{* *}$ & - & \\
Uncertainty & 3.12 & 1.02 & $-0.59^{* *}$ & -0.15 & -0.15 & - \\
\hline \multicolumn{7}{c}{ Note: ${ }^{* *} p<0.01}$.
\end{tabular}

\section{Results}

\subsection{Construct Validity and Common Method Bias}

The four-factor model provided an acceptable fit $\left(\chi^{2}=242.040, \mathrm{df}=84, p<0.01\right.$; $\mathrm{RMSEA}=0.08$; $\mathrm{CFI}=0.95$; NNFI = 0.94), and all the parameters estimated were statistically significant $(p<0.05)$. Results indicated that each item saturated in its corresponding scale. The fit of the single-factor model was not acceptable $\left(\chi^{2}=580.782, \mathrm{df}=90, p<0.01\right.$; RMSEA $=0.243$; CFI $=0.634$; NNFI =0.573). All the goodness-of-fit indexes were satisfactory for the four-factor model, whereas the single-factor model showed a poor fit to data (cut-off values in RMSEA were not reached). In sum, a single-factor model did not explain our data as well as the predicted model (four factors), in which the study variables were considered different constructs.

Referencing for the CFA marker technique to test common method bias, we tested and compared the models indicated in Table 3. Method-C $\left(\chi^{2} / \mathrm{df}=1.83, \mathrm{CFI}=0.89, \mathrm{RMSEA}=0.10\right)$ produced a better fitting model than Baseline $\left(\chi^{2} / \mathrm{df}=2.08, \mathrm{CFI}=0.85, \mathrm{RMSEA}=0.12\right), \Delta \chi^{2}=25.71, p<0.001$, indicating the presence of CMV. Method-U $\left(\chi^{2} / \mathrm{df}=1.69, \mathrm{CFI}=0.92, \mathrm{RMSEA}=0.10\right)$ provided a better model than Method-C, $\Delta \chi^{2}=31.07, p<0.001$, indicating that CMV is not equal across all indicators. Method-R, based on the better fitting Method-U, showed no significant differences from Method-U $\left(\Delta \chi^{2}=1.19, p=0.76\right)$, suggesting that CMV does not skew the relationship between the substantive variables.

Table 3. Confirmatory factor analysis (CFA) Marker Test for common method variance (CMV).

\begin{tabular}{|c|c|c|c|c|c|c|c|}
\hline Model & $\chi^{2}(\mathrm{df})$ & $\chi^{2} / \mathrm{df}$ & CFI & RMSEA $(90 \%$ CI) & $\Delta \chi^{2}$ & $\begin{array}{l}\text { Critical } \chi^{2} \\
(p=0.05)\end{array}$ & $\begin{array}{c}\text { Model } \\
\text { Comparison }\end{array}$ \\
\hline $\begin{array}{l}\text { CFA with } \\
\text { marker } \\
\text { variable }\end{array}$ & $\begin{array}{c}162.70 \\
(88)\end{array}$ & 1.85 & 0.90 & $0.10(0.08,0.13)$ & & & \\
\hline Baseline & $\begin{array}{c}203.50 \\
(98)\end{array}$ & 2.08 & 0.85 & $0.12(0.10,0.14)$ & & & \\
\hline Method-C & $\begin{array}{c}177.79 \\
(97)\end{array}$ & 1.83 & 0.89 & $0.10(0.08,0.12)$ & $\begin{array}{c}25.71^{* * *} \\
\Delta \mathrm{df}=1\end{array}$ & 3.84 & $\begin{array}{c}\text { vs. } \\
\text { Baseline }\end{array}$ \\
\hline Method-U & $\begin{array}{c}146.72 \\
(87)\end{array}$ & 1.69 & 0.92 & $0.10(0.07,0.12)$ & $\begin{array}{l}31.07^{* * *} \\
\Delta \mathrm{df}=10\end{array}$ & 18.31 & $\begin{array}{c}\text { vs. } \\
\text { Method-C }\end{array}$ \\
\hline Method-R & $\begin{array}{c}147.91 \\
(90)\end{array}$ & 1.64 & 0.92 & $0.09(0.06,0.11)$ & $\begin{array}{c}1.19 \\
(p=0.76) \\
\Delta \mathrm{df}=3\end{array}$ & 7.82 & $\begin{array}{c}\text { vs. } \\
\text { Method-U }\end{array}$ \\
\hline
\end{tabular}

Note: CFA = confirmatory factor analysis; $\mathrm{CFI}=$ comparative fit index; RMSEA = root mean square error of approximation; $\mathrm{C}=$ common; $\mathrm{U}=$ unconstrained; $\mathrm{R}=$ restricted; ${ }^{* * *} p<0.001$.

\subsection{Hypotheses Results}

As far as the mediation is concerned (Hypotheses 1 and 2), psychological safety (IV) was associated with individual proactive performance (DV) via challenging role orientation (mediator). Psychological safety was positively associated with individual proactive performance $(\mathrm{B}=0.26, t(81)=2.23, p<0.05)$ 
and with challenging role orientation $(\mathrm{B}=0.45, t(81)=4.18, p<0.001)$. Challenging role orientation was positively associated with individual proactive performance $(B=0.51, t(80)=5.34, p<0.001)$. Results of the mediation analyses confirmed the mediating role of a challenging role orientation in the relationship between psychological safety and individual proactive performance, $B=0.23$, CI $(0.09,0.40)$. Results also indicated that the direct effect of psychological safety on individual proactive performance became non-significant $(B=0.03, t(80)=0.32, p=0.75)$ when controlling for a challenging role orientation, thus revealing full mediation (see Table 4 ).

Table 4. Results of PROCESS mediation analysis.

\begin{tabular}{|c|c|c|c|c|}
\hline & $\begin{array}{c}\text { Mediator: } \\
\text { Challenging } \\
\text { Role Orientation }\end{array}$ & & & \\
\hline Effects & $B$ & $S E$ & $p$ & $95 \% \mathrm{CI}$ \\
\hline Upward psychological safety to mediator ( $a$ path) & 0.45 & 0.11 & $<0.001$ & $(0.23,0.66)$ \\
\hline \multirow[t]{3}{*}{$R^{2}$} & 0.23 & & & \\
\hline & $\begin{array}{l}\text { Outcome: proactive } \\
\text { performance }\end{array}$ & & & \\
\hline & $B$ & $S E$ & $p$ & $95 \% \mathrm{CI}$ \\
\hline Mediator to outcome ( $b$ path) & 0.51 & 0.10 & $<0.0001$ & $(0.32,0.70)$ \\
\hline $\begin{array}{c}\text { Total effect of upward psychological safety on } \\
\text { outcome (c path) }\end{array}$ & 0.26 & 0.12 & $<0.05$ & $(0.03,0.50)$ \\
\hline $\begin{array}{c}\text { Direct effect of upward psychological safety on } \\
\text { outcome ( } c^{\prime} \text { path) }\end{array}$ & 0.03 & 0.11 & 0.75 & $(-0.18,0.24)$ \\
\hline $\begin{array}{l}\text { Total indirect effect of upward psychological safety } \\
\text { on outcome through mediator ( } a b \text { path) }\end{array}$ & 0.23 & 0.07 & $<0.01$ & $(0.09,0.40)$ \\
\hline$R^{2}$ & 0.30 & & & \\
\hline
\end{tabular}

Regarding the moderated mediation (Hypothesis 3), analysis showed that, in addition to the previous mediation relationship among the three variables, uncertainty plays a moderating role. The values for the regression line slopes [75] were $0.16(t$-value $=6.81, p<0.01)$ for low uncertainty and 0.64 ( $t$-value $=10.5, p<0.01)$ for high uncertainty. The relationship between upward psychological safety and challenging role orientation was positive under both high and low levels of uncertainty. However, the effect of this relationship is different depending on the strength of uncertainty (the two slopes are not parallel, but crossed). The positive relationship is higher under higher levels of uncertainty. However, the effect of this relationship is different depending on the level of uncertainty (the two slopes are crossed), and the positive relationship is stronger under high perceived uncertainty. That is, individuals adopt the highest levels of a challenging work attitude when high psychological safety and high uncertainty are present at the same time. In order to make the interpretation of significant interaction effects easier, a graphic representation was created [76], in which we plotted critical upward communication against IC for low and high levels of job workload (Figure 2).

Finally, we examined the conditional indirect effect of upward psychological safety on proactive performance through challenging work orientation for three values of uncertainty: one standard deviation below the mean, the mean, and one standard deviation above the mean. As Table 5 shows, uncertainty enhanced the indirect effect of psychological safety on individual proactive performance through a higher challenging role orientation in high levels of uncertainty, $\mathrm{B}=0.33, \mathrm{CI}(0.17$ to 0.53$)$ and average levels of uncertainty, $\mathrm{B}=0.21, \mathrm{CI}(0.06,0.43)$, but not low levels of uncertainty, $\mathrm{B}=0.08$, $\mathrm{CI}(-0.12,0.38)$. It can be observed from the coefficients that the higher level of uncertainty contributed to a stronger effect of psychological safety on individual proactive performance through a higher challenging orientation. The moderated mediation model indicating direct and indirect mediated paths is displayed in Figure 3. 


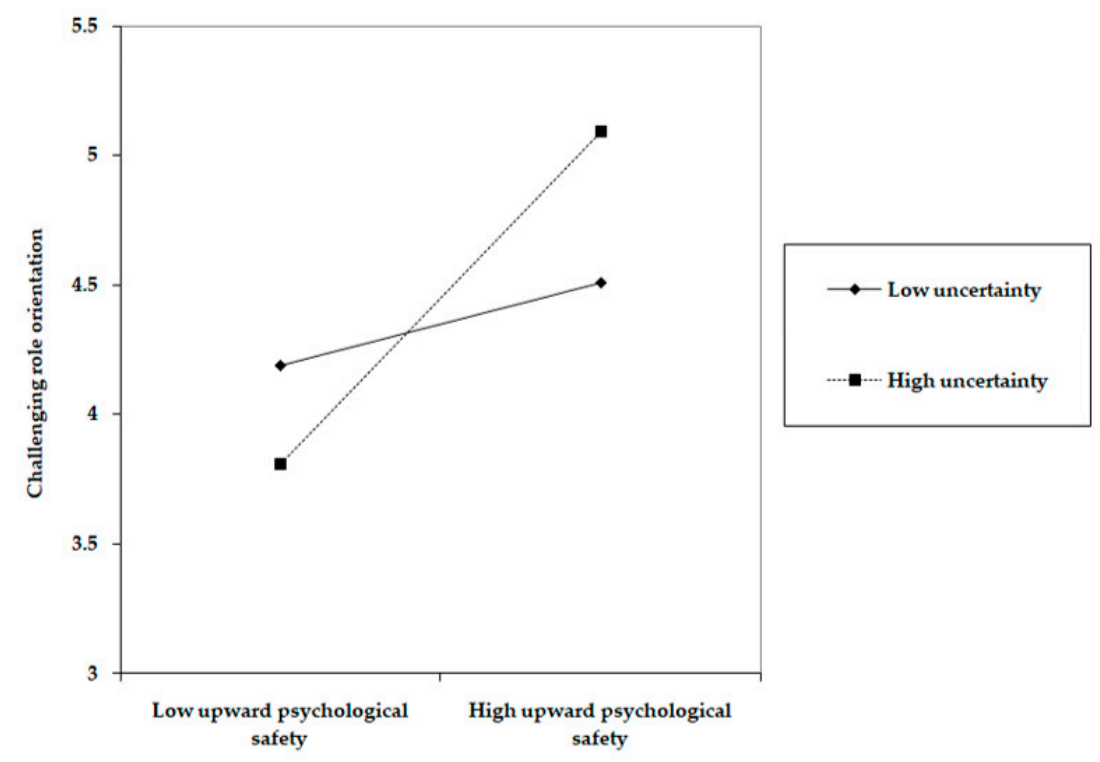

Figure 2. Interaction between upward psychological safety and uncertainty as predictors of a challenging role orientation.

Table 5. Results of PROCESS moderated mediation analysis.

\begin{tabular}{|c|c|c|c|c|}
\hline & $\begin{array}{l}\text { Mediator: } \\
\text { Challenging } \\
\text { Role Orientation }\end{array}$ & & & \\
\hline Effects & $B$ & $S E$ & $p$ & $95 \% \mathrm{CI}$ \\
\hline $\begin{array}{l}\text { Upward psychological safety to } \\
\text { mediator (a path) }\end{array}$ & 0.40 & 0.15 & $<0.01$ & $(0.11,0.69)$ \\
\hline \multirow[t]{3}{*}{$R^{2}$} & 0.28 & & & \\
\hline & $\begin{array}{l}\text { Outcome: } \\
\text { proactive } \\
\text { performance }\end{array}$ & & & \\
\hline & $B$ & $S E$ & $p$ & $95 \% \mathrm{CI}$ \\
\hline Mediator to outcome ( $b$ path) & 0.51 & 0.10 & $<0.0001$ & $(0.32,0.70)$ \\
\hline $\begin{array}{l}\text { Direct effect of upward psychological } \\
\text { safety on outcome ( } c^{\prime} \text { path) }\end{array}$ & 0.03 & 0.11 & 0.75 & $(-0.18,0.24)$ \\
\hline $\begin{array}{l}\text { Conditional indirect effects of upward } \\
\text { psychological safety on outcome at } \\
\text { values of uncertainty with challenging } \\
\text { role orientation as mediator }\end{array}$ & 0.24 & 0.12 & $<0.05$ & $(0.00,0.48)$ \\
\hline Low & 0.08 & 0.13 & & $(-0.12,0.38)$ \\
\hline Average & 0.21 & 0.09 & & $(0.06,0.43)$ \\
\hline High & 0.33 & 0.09 & & $(0.17,0.53)$ \\
\hline Index of Moderated Mediation & 0.12 & 0.06 & & $(0.01,0.26)$ \\
\hline
\end{tabular}




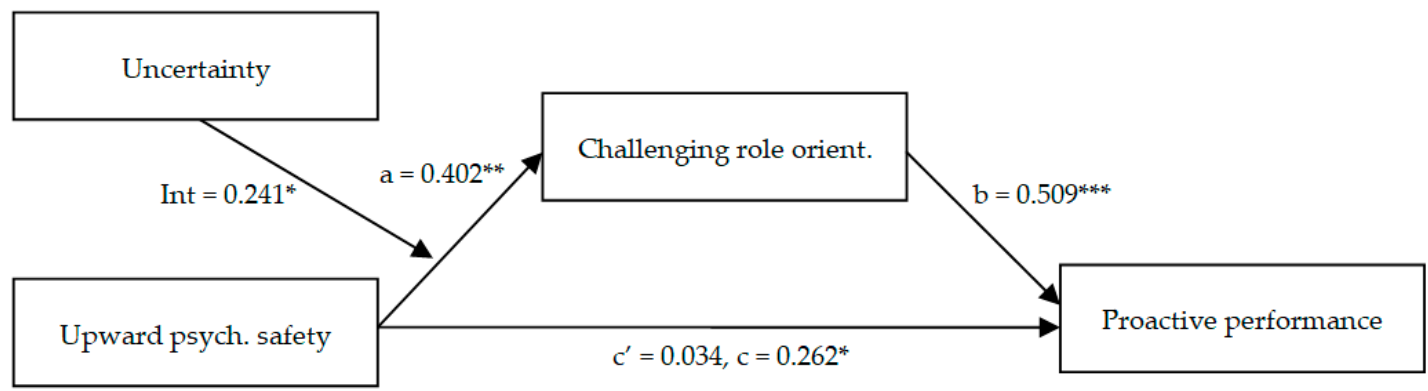

Figure 3. Moderated mediation model showing the moderating role of uncertainty. Note: ${ }^{*} p<0.05$; ** $p<0.01 ;{ }^{* * *} p<0.001$.

\section{Discussion}

The proliferation of startups in the Baltic region in recent years has gone unnoticed by international management researchers. The present study explored how these startups achieve proactivity to survive and evolve. In particular, the leader-follower relational factors contributing to the proactive performance were analyzed. On the one hand, we hypothesized that upward psychological safety would positively predict proactive performance via a challenging role orientation (Hypothesis 1) and directly (Hypothesis 2). Whereas upward psychological safety alone accounted for some variance in individual proactive performance (non-significant), upward psychological safety mediated by a challenging role orientation had significant predictive power on proactive performance, indicating full mediation. Thus, upward psychological safety did not exert a significant direct effect on proactive performance (Hypothesis 2 was rejected), but rather a mediated significant effect through a challenging role orientation (Hypothesis 1 was supported). On the other hand, we hypothesized that uncertainty would moderate the relationship between upward psychological safety and proactive performance via a challenging role orientation (Hypothesis 3). The results showed that under high levels of perceived uncertainty, the impact of psychological safety on a challenging role orientation (and by extension on proactive performance) was stronger (Hypothesis 3 was supported).

We believe that the results of our research could have three important implications for organizational and leadership research. First, to our knowledge, specific upward psychological safety has not been analyzed before. Psychological safety is still a nascent construct, and previous empirical studies conceptualized it generally, considering all the actors around the individual as safety providers, rather than focusing only on the leader. Thus, whereas general psychological safety refers to the belief that one can speak up and contribute without being punished or humiliated by those around them (e.g., peers and leaders), upward psychological safety refers only to the leader. In this regard, our study refines the concept of psychological safety towards the leader-follower relationship, and our results show the key role of upward psychological safety in influencing employee attitudes (challenging role orientation) and, ultimately, performance behaviors (proactive performance).

Second, the findings for full mediation support our distal-proximal hypothesized model and confirm the theoretical proposal [4] that proactive performance does not directly depend on relational components per se (i.e., psychological safety), but rather on the individual attitudes (i.e., challenging role orientation) they produce. In this case, we found that a relational dynamic such as upward psychological safety (distal cause) can influence the individual disposition to be more challenge-oriented toward work (proximal cause), resulting in proactive performance. Taking into consideration that research on psychological safety has mainly focused on its direct influence on proactive-related behaviors, our results open up a new research avenue to further identify other possible mechanisms through which psychological safety exerts its influence on performance behaviors.

Third, to date, there have been few attempts to find out how to capitalize on uncertainty and use it as a lever for improved performance. Our results advance knowledge about how to cope with uncertainty in order to benefit from it. In particular, our results are in line with the theory of 
management of uncertainty by Grote [20,71]. According to Grote [20], there are two approaches to handling uncertainty. On the one hand, "Minimizing uncertainty" is the approach that is still being followed by many organizations, and it is often favored in keeping systems under control. On the other hand, "Coping with uncertainty" is a relatively new approach where local actors need to be given more autonomy, more self-management, and more control over the environment to handle imperfect knowledge. In order to cope with uncertainty (rather than minimizing it), individuals need to actively explore and take action beyond the constant default work boundaries. Our results show that upward psychological safety is a positive predictor of a challenging role orientation and proactive performance in both predictable (low uncertainty) and unpredictable (high uncertainty) circumstances. However, it was much stronger and more effective in the latter case. This finding clears up doubts about the effect of uncertainty on proactive performance, as it empirically supports the speculation that some situational stressors (such as uncertainty) have a promoting effect on proactive performance [12]. In addition, it reveals the circumstances in which such an effect occurs.

The present study also has practical implications for startups and managers. First, our results recall the proverb "if you cannot beat your enemy, join him/her". Rather than trying to minimize uncertainty, startups must learn how to cope with and relate to it. Our results reveal that upward psychological safety is a powerful strategy to use to take advantage of uncertainty in small innovative startups because when there are high levels of uncertainty, psychological safety is more effective in promoting employees' active exploration and self-directed actions. Thus, this study presents an effective way to embrace and take advantage of uncertainty by enhancing employees' psychological safety from the top. Second, our model could help consultants and HR professionals in innovation-based firms to design leader training and situational dynamics in the workplace to encourage upward psychological safety. Some examples of strategies that leaders could use to make their followers feel safe are: framing the work as a learning problem rather than as an execution problem [77], acknowledging fallibility and being humble [78], or showing genuine curiosity about followers [16]. These explicit activities and strategies are designed to create the rationale for speaking up and encouraging initiative. Finally, this study provides managers with valuable insights into psychological safety specifically related to their role (upward psychological safety), as well as its functioning and outcomes in startups.

The present research has several limitations. Our variables were evaluated by self-report measures. Self-report measures provide valid information about the informants' perception of their work reality, but their exclusive use without any alternative measures could produce distorted results due to participants' tendency to answer in a consistent and socially desirable manner. Second, although we calculated a power analysis to determine the sample size needed for an appropriate power level, it would be preferable to have a larger and more representative sample that would allow us to present more robust results and provide additional support for our hypotheses. Future surveys to assess either team-level or organizational-level factors should involve a sufficiently large sample to include team or organizational scores and allow multilevel analyses to be conducted. Third, the cross-sectional nature of the research reduces the content of our variables to a snapshot, rather than providing a longitudinal evaluation that dynamically examines the proposed processes over time. Future longitudinal studies, especially for dynamic constructs like a challenging role orientation or proactive performance, would provide further validation of our model derived from a cross-sectional design.

Author Contributions: Both M.M.-C. and X.Z. were involved in the conceptualization, methodology, writing-original draft preparation, writing - review and editing, and project administration. All authors have read and agreed to the published version of the manuscript.

Funding: This research received no external funding.

Conflicts of Interest: The authors declare no conflict of interest. 


\section{References}

1. Battistella, C.; De Toni, A.F.; Pessot, E. Open accelerators for start-ups success: A case study. Eur. J. Innov. Manag. 2017, 20, 80-111. [CrossRef]

2. Frese, M.; Fay, D.; Hilburger, T.; Leng, K.; Tag, A. The concept of personal initiative: Operationalization, reliability and validity in two German samples. J. Occup. Organ. Psychol. 1997, 70, 139-161. [CrossRef]

3. Frese, M. The word is out: We need an active performance concept for modern workplaces. Ind. Organ. Psychol. 2008, 1, 67-69. [CrossRef]

4. Bindl, U.K.; Parker, S.K. Proactive work behavior: Forward-thinking and change oriented action in organizations. In APA Handbook of Industrial and Organizational Psychology; Zedeck, S., Ed.; American Psychological Association: Washington, DC, USA, 2010; pp. 567-598.

5. Parker, S.K.; Williams, H.M.; Turner, N. Modeling the antecedents of proactive behavior at work. J. Appl. Psychol. 2006, 91, 636-652. [CrossRef] [PubMed]

6. Edmondson, A.C. Psychological safety and learning behavior in work teams. Adm. Sci. Q. 1999, 44, 350-383. [CrossRef]

7. Edmondson, A.C. The Fearless Organization: Creating Psychological Safety in the Workplace for Learning, Innovation, and Growth; John Wiley \& Sons: Hoboken, NJ, USA, 2019.

8. Kramer, R.M.; Cook, K.S. Trust and Distrust in Organizations: Dilemmas and Approaches; Russell Sage Foundation: New York, NY, USA, 2004.

9. Detert, J.R.; Burris, E.R. Leadership behavior and employee voice: Is the door really open? Acad. Manag. J. 2007, 50, 869-884. [CrossRef]

10. Nembhard, I.M.; Edmondson, A.C. Making it safe: The effects of leader inclusiveness and professional status on psychological safety and improvement efforts in health care teams. J. Organ. Behav. 2006, 27, 941-966. [CrossRef]

11. Walumbwa, F.O.; Schaubroeck, J. Leader personality traits and employee voice behavior: Mediating roles of ethical leadership and work group psychological safety. J. Appl. Psychol. 2009, 94, 1275-1286. [CrossRef]

12. Fay, D.; Sonnentag, S. Rethinking the effects of stressors: A longitudinal study on personal initiative. J. Occup. Health Psychol. 2002, 7, 221-234. [CrossRef]

13. Sonnentag, S. Recovery, work engagement, and proactive behavior: A new look at the interface between nonwork and work. J. Appl. Psychol. 2003, 88, 518-528. [CrossRef]

14. Block, P. Stewardship: Choosing Service over Self Interest, 2nd ed.; Berrett-Koehler Publishers: San Francisco, CA, USA, 2013.

15. Schein, E.H. Reassessing the 'divine rights' of managers. MIT Sloan Manag. Rev. 1989, 30, 63-68.

16. Schein, E.H.; Schein, P.A. Humble Leadership: The Power of Relationships, Openness, and Trust; Berrett-Koehler Publishers: Oakland, CA, USA, 2018.

17. Carnoy, M.; Castells, M. Globalization, the knowledge society, and the Network State: Poulantzas at the millennium. Glob. Netw. 2001, 1, 1-18. [CrossRef]

18. Dardot, P.; Laval, C. Never Ending Nightmare: The Neoliberal Assault on Democracy; Verso Books: Brooklyn, NY, USA, 2019.

19. Weick, K.E.; Sutcliffe, K.M. Managing the Unexpected: Resilient Performance in An Age of Uncertainty, 2nd ed.; Jossey-Bass: New York, NY, USA, 2007.

20. Grote, G. Uncertainty management at the core of system design. Annu. Rev. Control 2004, 28, $267-274$. [CrossRef]

21. Crant, J.M. Proactive behavior in organizations. J. Manag. 2000, 26, 435-462. [CrossRef]

22. Grant, A.M.; Ashford, S.J. The dynamics of proactivity at work. Res. Organ. Behav. 2008, 28, 3-34. [CrossRef]

23. Frese, M.; Fay, D. Personal initiative: An active performance concept for work in the 21st century. Res. Organ. Behav. 2001, 23, 133-187. [CrossRef]

24. Parker, S.K. From passive to proactive motivation: The importance of flexible role orientations and role breadth self-efficacy. Appl. Psychol. Int. Rev. 2000, 49, 447-469. [CrossRef]

25. Rank, J.; Pace, V.L.; Frese, M. Three avenues for future research on creativity, innovation, and initiative. Appl. Psychol. Int. Rev. 2004, 53, 518-528. [CrossRef]

26. Shalley, C.E.; Zhou, J.; Oldham, G.R. The effects of personal and contextual characteristics on creativity: Where should we go from here? J. Manag. 2004, 30, 933-958. [CrossRef] 
27. Parker, S.K.; Bindl, U.K.; Strauss, K. Making things happen: A model of proactive motivation. J. Manag. 2010, 36, 827-856. [CrossRef]

28. Aragón-Correa, J.A. Strategic proactivity and firm approach to the natural environment. Acad. Manag. J. 1998, 41, 556-567. [CrossRef]

29. Griffin, M.; Neal, A.; Parker, S. A new model of work role performance: Positive behavior in uncertain and interdependent contexts. Acad. Manag. J. 2007, 50, 327-347. [CrossRef]

30. Katz, D.; Kahn, R.L. The Social Psychology of Organizations; Wiley: New York, NY, USA, 1978.

31. Parker, S.K. Enhancing role breadth self-efficacy: The roles of job enrichment and other organizational interventions. J. Appl. Psychol. 1998, 83, 835-852. [CrossRef] [PubMed]

32. Shukla, A.; Singh, S.; Rai, H.; Bhattacharya, A. Employee empowerment leading to flexible role orientation: A disposition-based contingency framework. IIMB Manag. Rev. 2018, 30, 330-342. [CrossRef]

33. Locke, E.A.; Latham, G.P. A Theory of Goal Setting and Task Performance; Prentice Hall: Englewood Cliffs, NJ, USA, 1990.

34. Parker, S.K. That is my job' How employees' role orientation affects their job performance. Hum. Relat. 2007, 60, 403-434. [CrossRef]

35. Davis, L.E.; Wacker, G.L. Job design. In Handbook of Human Factors; Salvendy, G., Ed.; Wiley: New York, NY, USA, 1987; pp. 431-452.

36. Parker, S.K.; Wall, T.D.; Jackson, P.R. That's not my job: Developing flexible employee work orientations. Acad. Manag. J. 1997, 40, 899-929. [CrossRef]

37. Martínez-Córcoles, M. High reliability leadership: A conceptual framework. J. Contingencies Crisis Manag. 2018, 26, 237-246. [CrossRef]

38. Den Hartog, D.N.; Belschak, F.D. When does transformational leadership enhance employee proactive behavior? The role of autonomy and role breadth self-efficacy. J. Appl. Psychol. 2012, 97, 194-202. [CrossRef]

39. Erkutlu, $\mathrm{H}$. The impact of organizational culture on the relationship between shared leadership and team proactivity. Team Perform. Manag. 2012, 18, 102-119. [CrossRef]

40. Schein, E.H. Humble Inquiry. In TRIAS Workshop on Culture, Process and Helping; Trias Institut für Coaching, Supervision und Organisationsentwicklung, Zurich, Switzerland. 2013. Available online: https://www.youtube.com/watch?v=GtV3Jx01BqU (accessed on 31 January 2020).

41. Edmondson, A.C.; Bohmer, R.M.; Pisano, G.P. Disrupted routines: Team learning and new technology implementation in hospitals. Adm. Sci. Q. 2001, 46, 685-716. [CrossRef]

42. Newman, A.; Donohue, R.; Eva, N. Psychological safety: A systematic review of the literature. Hum. Resour. Manag. Rev. 2017, 27, 521-535. [CrossRef]

43. Schein, E.H.; Bennis, W.G. Personal and Organizational Change through Group Methods: The Laboratory Approach; Wiley: New York, NY, USA, 1965.

44. Frazier, M.L.; Fainshmidt, S.; Klinger, R.L.; Pezeshkan, A.; Vracheva, V. Psychological safety: A meta-analytic review and extension. Pers. Psychol. 2017, 70, 113-165. [CrossRef]

45. Edmondson, A.C.; Lei, Z. Psychological safety: The history, renaissance, and future of an interpersonal construct. Annu. Rev. Organ. Psychol. Organ. Behav. 2014, 1, 23-43. [CrossRef]

46. Dirks, K.T.; Skarlicki, D.P. Trust in leaders: Existing research and emerging issues. In Trust and Distrust in Organizations: Dilemmas and Approaches; Kramer, R.M., Cook, K.S., Eds.; Russell Sage Foundation: New York, NY, USA, 2004; pp. 21-40.

47. Fulmer, C.A.; Gelfand, M.J. At What Level (and in Whom) We Trust: Trust across Multiple Organizational Levels. J. Manag. 2012, 38, 1167-1230. [CrossRef]

48. Ajzen, I. The theory of planned behavior. Organ. Behav. Hum. Decis. Process. 1981, 50, 179-211. [CrossRef]

49. Ajzen, I.; Madden, T.J. Prediction of goal-directed behavior: Attitudes, intentions, and perceived behavioral control. J. Exp. Soc. Psychol. 1986, 22, 453-474. [CrossRef]

50. Carmeli, A.; Gittell, J.H. High-quality relationships, psychological safety, and learning from failures in work organizations. J. Organ. Behav. 2009, 30, 709-729. [CrossRef]

51. Parker, S.K.; Wu, C.H. Leading for proactivity: How leaders cultivate staff who make things happen. In Oxford Library of Psychology. The Oxford Handbook of Leadership and Organizations; Day, D.V., Ed.; Oxford University Press: Oxford, UK, 2014; pp. 380-403.

52. Kolltveit, B.J.; Karlsen, J.T.; Grønhaug, K. Exploiting opportunities in uncertainty during the early project phase. J. Manag. Eng. 2004, 20, 134-140. [CrossRef] 
53. Dönmez, D.; Grote, G. Two sides of the same coin-how agile software development teams approach uncertainty as threats and opportunities. Inf. Softw. Technol. 2018, 93, 94-111. [CrossRef]

54. McPherson, K. Opinion-related information seeking: Personal and situational variables. Personal. Soc. Psychol. Bull. 1983, 9, 116-124. [CrossRef]

55. Kramer, M.W. Motivation to reduce uncertainty: A reconceptualization of uncertainty reduction theory. Manag. Commun. Q. 1999, 13, 305-316. [CrossRef]

56. Cordery, J.L.; Morrison, D.; Wright, B.M.; Wall, T.D. The impact of autonomy and task uncertainty on team performance: A longitudinal field study. J. Organ. Behav. 2010, 31, 240-258. [CrossRef]

57. Faul, F.; Erdfelder, E.; Lang, A.G.; Buchner, A. G*Power 3: A flexible statistical power analysis program for the social, behavioral, and biomedical sciences. Behav. Res. Methods 2007, 39, 175-191. [CrossRef] [PubMed]

58. Faul, F.; Erdfelder, E.; Buchner, A.; Lang, A.G. G*Power, version 3.1.2; Uiversität Kiel: Kiel, Germany, 2008; Available online: http://www.psycho.uni-duesseldorf.de/abteilungen/aap/gpower3/download-and-register (accessed on 29 January 2019).

59. IBM Corp. IBM SPSS Statistics for Windows, version 23.0; IBM Corp.: Armonk, NY, USA, 2015.

60. Arbuckle, J.L. Amos, version 23.0; IBM SPSS: Chicago, IL, USA, 2014.

61. Martínez-Córcoles, M.; Stephanou, K.D.; Schöbel, M. Exploring the effects of leaders' individualized consideration in extreme contexts. J. Risk Res. 2020, 23, 167-180. [CrossRef]

62. Colquitt, J.A.; Lepine, J.A.; Piccolo, R.F.; Zapata, C.P.; Rich, B.L. Explaining the justice-performance relationship: Trust as exchange deepener or trust as uncertainty reducer? J. Appl. Psychol. 2012, 97, 1-15. [CrossRef] [PubMed]

63. Tims, M.; Bakker, A.B.; Derks, D. Development and validation of the job crafting scale. J. Vocat. Behav. 2012, 80, 173-186. [CrossRef]

64. Jöreskog, K.G.; Sörbom, D. LISREL 8.80 for Windows; Scientific Software International, Inc.: Lincolnwood, IL, USA, 2006.

65. Podsakoff, P.M.; MacKenzie, S.B.; Lee, J.Y.; Podsakoff, N.P. Common method biases in behavioral research: A critical review of the literature and recommended remedies. J. Appl. Psychol. 2003, 88, 879-903. [CrossRef]

66. Browne, M.W.; Cudeck, R. Alternative ways of assessing model fit. In Testing Structural Equation Models; Bollen, K.A., Long, J.S., Eds.; Sage: Newbury Park, CA, USA, 1993; pp. 136-162.

67. Browne, M.W.; Du Toit, S.H.C. Automated fitting of nonstandard model. Multivar. Behav. Res. 1992, 27, 269-300. [CrossRef]

68. Marsh, H.W.; Hau, K.T.; Grayson, D. Goodness of fit in structural equation models. In Contemporary Psychometrics: A Festschrift for Roderick P. McDonald; Maydeu-Olivares, A., McArdle, J.J., Eds.; Lawrence Erlbaum Associates: Mahwah, NJ, USA, 2005; pp. 225-340.

69. Richardson, H.A.; Simmering, M.J.; Sturman, M.C. A tale of three perspectives: Examining post hoc statistical techniques for detection and correction of common method variance. Organ. Res. Methods 2009, 12, 762-800. [CrossRef]

70. Williams, L.J.; Hartman, N.; Cavazotte, F. Method variance and marker variables: A review and comprehensive CFA marker technique. Organ. Res. Methods 2010, 13, 477-514. [CrossRef]

71. Grote, G. Management of Uncertainty_Theory and Application in the Design of Systems and Organizations; Springer: London, UK, 2009.

72. Miller, D.; Friese, P. Innovation in conservative and entrepreneurial firms: Two models of strategic momentum. Strateg. Manag. J. 1982, 3, 1-25. [CrossRef]

73. Simmering, M.J.; Fuller, C.M.; Richardson, H.A.; Ocal, Y.; Atinc, G.M. Marker variable choice, reporting, and interpretation in the detection of common method variance: A review and demonstration. Organ. Res. Methods 2015, 18, 473-511. [CrossRef]

74. Hayes, A.F. Introduction to Mediation, Moderation, and Conditional Process Analysis: A Regression-Based Approach; The Guilford Press: New York, NY, USA, 2013.

75. Aiken, L.S.; West, S.G. Multiple Regression: Testing and Interpreting Interactions; Sage Publications: Thousand Oaks, CA, USA, 1991.

76. Dawson, J.F.; Richter, A.W. Probing three-way interactions in moderated multiple regression: Development and application of a slope difference test. J. Appl. Psychol. 2006, 91, 917-926. [CrossRef] [PubMed] 
77. Edmondson, A.C. Building a Psychologically Safe Workplace. TEDxHGSE Talk. 2014. Available online: https://www.youtube.com/watch?v=LhoLuui9gX8 (accessed on 27 January 2020).

78. Schein, E.H. Helping: How to Offer, Give, and Receive Help; Berrett-Koehler Publishers: San Francisco, CA, USA, 2009.

Publisher's Note: MDPI stays neutral with regard to jurisdictional claims in published maps and institutional affiliations.

(C) 2020 by the authors. Licensee MDPI, Basel, Switzerland. This article is an open access article distributed under the terms and conditions of the Creative Commons Attribution (CC BY) license (http://creativecommons.org/licenses/by/4.0/). 